\title{
A qPCR method for distinguishing biomass from non-axenic terrestrial cyanobacteria cultures in hetero- or mixotrophic cultivations
}

\author{
Jakob Walther ${ }^{1}$ (D) Anna Schwarz ${ }^{2}$ (D) Marco Witthohn ${ }^{2}$ (D) Dorina Strieth $^{1}$ (D) $\cdot$ Kai Muffler $^{2}$ (D) Roland Ulber $^{1}$ (D)
}

Received: 25 June 2020 / Revised and accepted: 23 September 2020 / Published online: 15 October 2020

(C) The Author(s) 2020

\begin{abstract}
The cultivation of cyanobacteria with the addition of an organic carbon source (meaning as heterotrophic or mixotrophic cultivation) is a promising technique to increase their slow growth rate. However, most cyanobacteria cultures are infected by non-separable heterotrophic bacteria. While their contribution to the biomass is rather insignificant in a phototrophic cultivation, problems may arise in heterotrophic and mixotrophic mode. Heterotrophic bacteria can potentially utilize carbohydrates quickly, thus preventing any benefit for the cyanobacteria. In order to estimate the advantage of the supplementation of a carbon source, it is essential to quantify the proportion of cyanobacteria and heterotrophic bacteria in the resulting biomass. In this work, the use of quantitative polymerase chain reaction (qPCR) is proposed. To prepare the samples, a DNA extraction method for cyanobacteria was improved to provide reproducible and robust results for the group of terrestrial cyanobacteria. Two pairs of primers were used, which bind either to the $16 \mathrm{~S}$ rRNA gene of all cyanobacteria or all bacteria including cyanobacteria. This allows a determination of the proportion of cyanobacteria in the biomass. The method was established with the two terrestrial cyanobacteria Trichocoleus sociatus SAG 26.92 and Nostoc muscorum SAG B-1453-12a. As proof of concept, a heterotrophic cultivation with $T$. sociatus with glucose was performed. After 2 days of cultivation, a reduction of the biomass partition of the cyanobacterium to $90 \%$ was detected. Afterwards, the proportion increased again.
\end{abstract}

Keywords Terrestrial cyanobacteria $\cdot \mathrm{qPCR} \cdot$ Heterotrophic cultivation $\cdot$ Mixotrophic cultivation $\cdot$ Phototrophic biofilms

\section{Introduction}

Cyanobacteria are an interesting source of natural bioactive compounds (Chlipala et al. 2011) that possess antibacterial (Gantar et al. 2011; Lamprinou et al. 2015), antimycotic (Swain et al. 2017) and anticancer (Kinghorn et al. 2016) activity. Terrestrial cyanobacteria, particularly, form an interesting subgroup of previously uninvestigated diversity (Garcia-Pichel et al. 2001). They produce energy via photosynthesis and are therefore normally cultivated in mineral salt

Electronic supplementary material The online version of this article (https://doi.org/10.1007/s10811-020-02282-2) contains supplementary material, which is available to authorized users.

Roland Ulber

ulber@mv.uni-kl.de

1 Institute of Bioprocess Engineering, University of Kaiserslautern, Gottlieb-Daimler-Str. 49, 67663 Kaiserslautern, Germany

2 Department of Life Sciences and Engineering, University of Applied Sciences Bingen, Berlinstr. 109, 55411 Bingen, Germany medium (e.g. BG11 or Z8) (Allen 1968) under light. Phototrophic cultivation leads to slow growth rates $(\sim 0.1-$ 0.5 day $^{-1}$ ) (Chojnacka and Noworyta 2004; Kuhne et al. 2014). In addition, the necessary light supply makes the upscaling of cultivation systems more difficult and requires special photobioreactors (Strieth et al. 2018). The production of biomass for the investigation of natural substances is thus severely restricted. One possibility to avoid this limitation is cultivation with the addition of carbohydrates (Yu et al. 2009; Trabelsi et al. 2013). If the cyanobacteria metabolize these in addition to the photosynthesis, they can produce extra biomass (mixotrophic cultivation) (Chojnacka and Noworyta 2004). Furthermore, heterotrophic cultivation without illumination would offer the possibility of cultivation in large scale in the widely used and well-characterized stirred tank bioreactors.

Another problem during culturing cyanobacteria is adherent heterotrophic bacteria. Some of these bacteria cannot be completely removed from the cultures, even with complex isolation procedures (Ferris and Hirsch 1991; Palinska and Krumbein 1995; Temraleeva et al. 2016; Vasquez-Martinez 
et al. 2004). Many of these bacteria, such as Bacillus species, show very high growth rates under optimal nutrient conditions $\left(\mu>1 \mathrm{~h}^{-1}\right)$. Therefore, if a carbohydrate is added to cyanobacteria cultivated under phototrophic conditions, it is possible that a heterotrophic bacterium will use most of it. This falsifies the measured growth rate for the cyanobacterium. The growth of cyanobacteria is usually measured via the cell dry weight or the optical density of the cell suspension. However, both methods do not distinguish between cyanobacteria and heterotrophic bacteria. This means that no reliable conclusions can be drawn about the growth of cyanobacteria, because the growth of heterotrophic bacteria also influences the measured parameters. Consequently, the composition of the biomass must be measured during cultivation to determine the level of contamination. The simplest variant is microscopic evaluation where the cells of the different species can be distinguished and counted to determine the composition of the biomass. However, this method is only suitable for the quantification of similarly sized cells such as microalgae and cyanobacteria (Arias et al. 2019). Yet cyanobacteria are about $10 \mu \mathrm{m}$ in size and many heterotrophic bacteria are only about $2 \mu \mathrm{m}$. In addition, this is relatively labour- and time-intensive and requires high amounts of experience for the correct delineation between organisms. Moreover, bacteria within a biofilm of cyanobacteria cannot be quantified well. They are often located very close to and between the cells of cyanobacteria and therefore cannot be distinguished from them. Another technique for contamination determination is the use of automated fluorescencebased cell sorting (FACS), where each individual cell is sorted and subsequently counted automatically (Zhou et al. 2018). The differentiation when sorting is accomplished by the inherent auto-fluorescence of the cyanobacteria. This enables the small heterotrophic bacteria to be easily distinguished from the larger cyanobacteria. A FACS can only count single cells. Therefore, this method is limited to planktonically growing cyanobacteria and not suitable for filamentous- or biofilmforming species.

An alternative to the aforementioned methods is the use of PCR. In the field of water monitoring, there have long been approaches to detect the occurrence of cyanobacteria, which are able to produce harmful cyanotoxins (Zhang et al. 2014). For this purpose, primers were established to detect genes necessary for toxin synthesis (Pacheco et al. 2016). A proven method for the detection of non-harmful strains has been established by the use of primers, targeting conserved regions of the 16S rRNA gene (Nübel et al. 1997). Although this method seems promising, there are inherent challenges that arise when extracting DNA from cyanobacteria. The most apparent difficulty is the production of mucilaginous polysaccharides by the cyanobacteria, which hinders cell lysis and interferes with most DNA extraction protocols (Porter 1988). One popular method, based on the use of xanthogenate, can lyse the cell walls effectively and forms insoluble aggregates from proteins and cell debris. These can then be removed immediately after extraction to achieve high initial sample purity (Tillett and Neilan 2000).

Other authors (Heck et al. 2016) presented a qPCR method to investigate the success of methods for the purification of Fischerella sp. CENA161. In this method, the 16S rRNA gene of cyanobacteria and bacteria were quantified using an external plasmid DNA standard. The ratio of the copy numbers was taken as a measure for the purity of the sample. It was shown that the additional steps of the treatment with sodium hypochlorite and detergent washing increased the DNA content of the cyanobacteria in the culture from 70 to $90 \%$. However, there was no correlation to the proportion of cyanobacterial biomass.

This work presents a qPCR method for quantifying the biomass fraction of cyanobacteria in cultivations with a carbohydrate source. The DNA of two cyanobacteria (Trichocoleus sociatus and Nostoc muscorum) was purified with an advanced xanthogenate method and quantified with two 16S rRNA gene primer sets. The biomass in the samples was then quantified by correlation with a standard curve. The cyanobacterium $T$. sociatus was cultivated heterotrophic with glucose. The composition of the biomass after 2, 5, 7 and 14 days was determined.

\section{Material and methods}

\section{Strains and cultivation}

The cyanobacteria studied (Trichocoleus sociatus DSM 109967/SAG 26.92 and Nostoc muscorum SAG B-1453$12 a$; both obtained from the strain collection of Professor Büdel, Department of Plant Ecology and Systematics, TUK) were cultivated under phototropic conditions at 100 $\mu$ mol $_{\text {Photons }} \mathrm{m}^{-2} \mathrm{~s}^{-1}, 27^{\circ} \mathrm{C}$ and $120 \mathrm{rpm}$ in an illuminated shaker (Multitron, Infors, Switzerland). Cultivation took place in $500-\mathrm{mL}$ shaking flasks without baffles in BG11 medium (Allen 1968). The biomass was inoculated into flasks with fresh media at regular intervals of 4 weeks for strain maintenance. For the heterotrophic cultivation, $2 \mathrm{~g} \mathrm{~L}^{-1}$ cell wet weight (cww) in a modified BG11 medium with $2.53 \mathrm{~g} \mathrm{~L}^{-1}$ glucose was cultivated for 14 days at $27{ }^{\circ} \mathrm{C}$ without illumination.

All bacteria (Bacillus subtilis DSM618, Bacillus sp. (own wild-type isolate from culture T. sociatus) and Escherichia coli K12 JM109 DSM3423) were cultivated in MuellerHinton-Bouillon (Carl Roth, Germany) for $17 \mathrm{~h}$ at $37{ }^{\circ} \mathrm{C}$ and $150 \mathrm{rpm}$. Saccharomyces cerevisiae DSM3799 was cultivated in YPG medium (yeast extract $10 \mathrm{~g} \mathrm{~L}^{-1}, 20 \mathrm{~g} \mathrm{~L}^{-1}$ soy peptone, $20 \mathrm{~g} \mathrm{~L}^{-1}$ glucose) at $30^{\circ} \mathrm{C}$ and $24 \mathrm{~h}$ at $150 \mathrm{rpm}$. 


\section{DNA extraction}

For DNA extraction from cyanobacteria the method developed by Tillet and Neilan (2000) was modified. This method is based on the use of an extraction buffer ( $1 \%$ potassium ethyl xanthogenate, $1 \%$ sodium dodecyl sulfate, $100 \mathrm{mM}$ Tris, $20 \mathrm{mM}$ EDTA, $800 \mathrm{mM}$ ammonium acetate, $\mathrm{pH}$ 8.0). The buffer breaks down the cells and extracts the DNA directly; a separate cell disruption is not necessary. However, in order to extract the DNA from the pellet-like growing biomass, a short treatment in a ball mill was added in this work upstream. The ball mill disintegrates the pellet so that the buffer can penetrate the cell well. To increase the purity of the DNA, also a phenol-chloroform extraction after the DNA extraction was added in this study. Approximately $50 \mathrm{mg}$ cww of fresh cyanobacteria was suspended in $400 \mu \mathrm{L}$ TE buffer $(10 \mathrm{mM}$ Tris, $1 \mathrm{mM}$ EDTA, pH 8.0) and a stainless steel ball (3.75 mm diameter, Heinrich Amelung GmbH, Germany) was added. The sample was then crushed for $1 \mathrm{~min}$ at a frequency of $30 \mathrm{~s}^{-1}$ in the ball mill (MM 301, Retsch, Germany). The cells were separated by centrifugation at $12,000 \times g$ for $10 \mathrm{~min}$. The supernatant was collected. The pellet was resuspended with $600 \mu \mathrm{L}$ freshly prepared extraction buffer and incubated for $60 \mathrm{~min}$ at $70{ }^{\circ} \mathrm{C}$ and $900 \mathrm{rpm}$ in a thermo shaker (TS-100, Biosan, Latvia). Afterwards, it was cooled on ice for $30 \mathrm{~min}$. The remaining cell debris were separated by centrifugation at $12,000 \times g$ for $10 \mathrm{~min}$. Both supernatants were pooled and the DNA was extracted with $1 \mathrm{~mL}$ phenol-chloroform-isoamyl alcohol mixture $\mathrm{pH} 8.0$ (product number 0883, VWR, PA, USA). For this, the two phases were mixed for $1 \mathrm{~min}$ in the ball mill with a frequency of $30 \mathrm{~s}^{-1}$. The two phases were then separated in the centrifuge for $10 \mathrm{~min}$ at $12,000 \times \mathrm{g}$. Eight hundred microliters of the aqueous top phase was reextracted with $800 \mu \mathrm{L}$ chloroform using the same procedure. Subsequently, the DNA in $700 \mu \mathrm{L}$ of the aqueous top-phase was precipitated with $700 \mu \mathrm{L}$ of ice-cold 2-propanol for $18 \mathrm{~h}$ at $-20{ }^{\circ} \mathrm{C}$. The DNA was separated by centrifugation at $12,000 \times g$ for $10 \mathrm{~min}$ at $4{ }^{\circ} \mathrm{C}$. The pellet was washed with ice-cold $70 \%$ ethanol, then air-dried and dissolved in $100 \mu \mathrm{L}$ TE buffer.

The DNA of the bacteria and yeasts for the analysis of the primer specificity were extracted with the GenElute Bacterial Genomic DNA Kit (Sigma-Aldrich, USA) according to the manual.

The concentration and purity of DNA was determined using a NanoDrop 2000 spectrophotometer (Thermo Fisher Scientific, USA).

\section{qPCR}

Two primer pairs were used for the qPCR. Primer pair (PP) Cya (Cya359F: GGG GAA T(C/T)T TCC GCA ATG GG and Cya781R: GAC TAC TGG GGT ATC
TAA TCC CAT T (Nübel et al. 1997)) binds specifically to the 16S rRNA gene sequence of cyanobacteria. Primer pair Bak (COR-F: CCATGAAGTCGGAA TCGCTAG and COR-R: ACTCCCATGGGTGT GACGG (Corless et al. 2000)) binds specifically to the 16S rRNA gene sequence of all bacteria including cyanobacteria. The primers were ordered Lab-Ready $(100 \mu \mathrm{M}$ in IDTE buffer, $\mathrm{pH} 8.0)$ and standard desalted (Integrated DNA Technologies, USA). The Cya forward primer was supplied as an equimolar mixture of $\mathrm{C}$ and $\mathrm{T}$, respectively, at position 8 . The PCR was performed in 96-well MTPs (catalogue number HSP9601, Biorad, USA), which were manually sealed with adhesive foils (catalogue number MSB1001, Biorad, USA). The entire qPCR preparation was performed manually under a fume hood at room temperature. Approximately $5 \mathrm{ng}$ DNA, $0.1 \mu \mathrm{M}$ primer and $10 \mu \mathrm{L}$ Mastermix (SsoAdvanced Universal SYBR Green Supermix, Biorad, USA) were used and filled up with DNA-free water for a final volume of $20 \mu \mathrm{L}$. The qPCR was performed in a CFX Connect System (Bio-Rad, USA) with the following parameters: Initial $3 \mathrm{~min} 98{ }^{\circ} \mathrm{C}$; 40 cycles 15 s $98{ }^{\circ} \mathrm{C}, 10 \mathrm{~s} 53{ }^{\circ} \mathrm{C}, 50 \mathrm{~s} 60{ }^{\circ} \mathrm{C}$. The cycle threshold values $(\mathrm{Cq})$ were determined by the CFX Maestro software (Version 4.1.2433.1219; Biorad, USA) using the single threshold method. The qPCR products were tested by default with a melting curve (65-95 ${ }^{\circ} \mathrm{C}, 0.5{ }^{\circ} \mathrm{C}$ steps). The melting point of PP Cya product was $86.5{ }^{\circ} \mathrm{C}$, that of PP Bak $87.5^{\circ} \mathrm{C}$. In method development, the product length was regularly checked using a $1.5 \%$ agarose gel in TAE buffer using a low-range ladder (GeneRuler Low Range DNA; Thermo Fisher Scientific, USA). The amplicon length was determined for the example of $T$. sociatus (NCBI accession number EF654080.1) in silico. Amplicon Cya starts at bp 303 and ends at bp 728, is $425 \mathrm{bp}$ long and has a GC content of $53.4 \%$. Amplicon Bak starts at bp 1252 and ends at bp 1343, is $91 \mathrm{bp}$ long and has a GC content of $60.4 \%$. The amplicons were checked for secondary structures via the mfold web server (Markham and Zuker 2005; Keith 2008). Using the relevant PCR parameters $\left(53{ }^{\circ} \mathrm{C}\right.$, concentrations of $50 \mathrm{mM} \mathrm{Na}^{+}$and $\left.0 \mathrm{mM} \mathrm{Mg}^{++}\right)$, structures with a free energy of $4.77 \mathrm{kcal} \mathrm{mol}^{-1}$ for PP Cya and - $3.24 \mathrm{kcal} \mathrm{mol}^{-1}$ for PP Bak were predicted (see Supplemental S3 and S4). The Cya primers used were examined for their specificity using NCBI-BlastN. The entire nucleotide collection was tested, excluding cyanobacteria (ID 1117). Additionally, uncultured/environmental sample sequences were excluded and otherwise the standard parameters for short sequences were used. The forward primer was not specific, e.g. it annealed to B. subtilis DSM618. For the reverse primer, only hits were found 
against chloroplasts that are related to cyanobacteria and mycoplasmas that are also related at the 16sRNA gene level.

\section{Primer efficiency}

To determine the efficiency of the primers, a dilution series was prepared and the $\mathrm{Cq}$ values for both primer pairs were determined by the qPCR method as a technical triplicate. For this purpose, the DNA of T. sociatus (initial concentration in qPCR $20 \mathrm{ng} \mu \mathrm{L}^{-1}$ ) was diluted with water in 1:10 steps. The efficiency (E) of the primers was calculated in the linear range using the following equation (Svec et al. 2015):

$E=\left(10^{-\left(\frac{1}{x}\right)}-1\right) * 100$

where $X$ is the slope of the linear regression of the qPCR threshold $(\mathrm{Cq})$ value over the logarithmic template concentration. The slope was determined using a linear fit in Origin 2019 (version 9.6.0.172; OriginLab Corporation, USA).

\section{Calibration curve}

For calibration, mixtures of 70 to $100 \%$ dry weight percent (wt $\%$ ) of $T$. sociatus respectively 60 to $100 \%$ for $N$. muscorum together with B. subtilis DSM 618 were used (e.g. $60 \%$ wt $\%$ cyanobacterium means that $1 \mathrm{~g}$ cell dry weight (cdw) contains $600 \mathrm{mg}$ of the respective cyanobacterium and $400 \mathrm{mg} \mathrm{B}$. subtilis). Bacillus subtilis was cultivated overnight in $100 \mathrm{~mL}$ LB medium (Carl-Roth, Germany) in a 500-mL shaking flask with baffles at $160 \mathrm{rpm}$ and $37^{\circ} \mathrm{C}$ for $12 \mathrm{~h}$. The DNA of the mixtures was extracted and purified with the protocol for cyanobacteria. Then, a qPCR was performed with the DNA preparations using both primer pairs. Biological triplicates were measured in technical triplicates.

The $\mathrm{Cq}$ for the amplification of the Cya primer was corrected by the $\mathrm{Cq}$ of the Bak Primer by subtraction (Eq. 2) to compensate for possible differences in the absolute DNA concentration in the PCR well according to Livak and Schmittgen (2001). This could arise from measuring the DNA concentration in the sample and from pipetting error.

$\Delta C q=C q_{C y a}-C q_{B a k}$

The resulting $\Delta \mathrm{Cq}$ was then used to generate the calibration function. Equation 3 was used to fit the data points:

$\Delta C q=a \cdot e^{-\frac{\text { partition } c d w_{\text {cyanobacteria }}}{b}}+c$ with $a, b$ and $c$ as empirical parameters and

partition $c d w_{\text {cyanobacteria }}$

$$
=\frac{c d w_{\text {cyanobacteria }}}{c d w_{\text {cyanobacteria }}+c d w_{B \text {. subtilis }}} * 100
$$

The empirical parameters were determined using the ExpDec1 function with Origin 2019.

\section{Results and discussion}

\section{DNA extraction}

The method according to Tillett and Neilan (2000) was extended with a chloroform phenol extraction to increase the purity of the obtained DNA. Although we successfully extracted DNA with this method, the reproducibility and robustness were insufficient. The studied cyanobacteria form pellets of up to $0.5 \mathrm{~cm}$ diameter, and therefore, the cells inside the pellet cannot be penetrated well for DNA extraction with XS buffer. A short pre-treatment in a ball mill was therefore applied. This disrupts the pellets and allows the XS buffer to effectively extract the DNA from the separated cells. The treatment in the ball mill is kept as brief as possible in order not to break up cells. But because this cannot be definitely excluded, the supernatant was kept and then combined with the extract for purification. For phototrophic culture of $T$. sociatus, a DNA yield of $2.29 \pm 0.02 \mu \mathrm{g}_{\mathrm{DNA}} \mathrm{mg}_{\mathrm{cdw}}{ }^{-1}$ or $151 \pm 1.6 \mathrm{ng}_{\mathrm{DNA}} \mathrm{mg}_{\mathrm{cww}}{ }^{-1}$ and for $N$. muscorum a yield of 3.49 $\pm 0.74 \mu \mathrm{g}_{\mathrm{DNA}} \mathrm{mg}_{\mathrm{cdw}}{ }^{-1}$ or $230 \pm 49 \mathrm{ng}_{\mathrm{DNA}} \mathrm{mg}_{\mathrm{cww}}{ }^{-1}$ can be achieved. For mixotrophic and heterotrophic cultures of T. sociatus, median yields of $149 \mathrm{ng}_{\mathrm{DNA}} \mathrm{mg}_{\mathrm{cww}}{ }^{-1}$ were achieved. With the initial method, higher overall yields of $12.7 \pm 6.0 \mu \mathrm{g} \mathrm{mg}_{\mathrm{cdw}}{ }^{-1}$ were achieved (Tillett and Neilan 2000). However, other cyanobacteria were examined. The yields are strain and order specific. For the strains which, like the $N$. commune examined here, belong to the order of Nostocales, Tillet and Neilan (2000) found smaller yields of $9.25 \pm 3.27 \mu \mathrm{g} \mathrm{mg}_{\mathrm{cdw}}{ }^{-1}$. In this work, a purification with phenol-chloroform extraction was also implemented. This probably reduces the yield. In any case, the DNA yields achieved were sufficient for the qPCR analyses performed. The purity of the purified DNA was determined by the quotient of adsorption at 260 and $280 \mathrm{~nm}$ in the NanoDrop. The value of $1.9964 \pm 0.1395$ can be considered sufficiently pure.

\section{Primer and calibration curve}

The aim was to develop a method to determine the exact composition of the biomass of a co-culture of cyanobacteria and heterotrophic bacteria. However, two characteristics of 
the non-axenic cultures prevented a standard absolute quantification. Firstly, there are no pure cultures of the quantified cyanobacteria, so that no direct standard curves can be generated. Second, the exact composition of the heterotrophic cocultures is unknown, so no specific primers can be selected for them. The composition could certainly be determined relatively precisely for the individual cultures by means of complex microbiological and genetic methods, but this was not the approach of this work. The aim was to develop a method that could be quickly transferred to any other cyanobacterial culture. Therefore, two primer pairs were selected based on the literature. Primer pair Cya (Nübel et al. 1997) binds specifically to the 16sRNA sequence of all cyanobacteria. Primer pair Bak (Corless et al. 2000) binds to the 16S rRNA gene sequence of all bacteria including cyanobacteria. Better would be an additional pair of primers that bind all bacteria except cyanobacteria, but we do not know of any such primers. Both can be annealed at the same temperature $\left(53{ }^{\circ} \mathrm{C}\right)$ and thus analyzed in the same PCR run. The specificity of the two primer pairs was tested against two cyanobacteria (T. sociatus and N. muscorum), two Gram-positive bacteria (B. subtilis and B. spec.), one Gram-negative bacterium (E. coli K12) and one yeast strain (S. cerevisiae, as negative control) (see Fig. 1).

The Cya primer achieved a Cq value significantly below the no template control (NTC) for the two tested cyanobacteria. The remaining bacteria and the yeast had a signal at the level of the NTC. It can therefore be confirmed that the Cya primers only amplifies cyanobacterial DNA. Nübel (Nübel et al. 1997) already successfully tested the

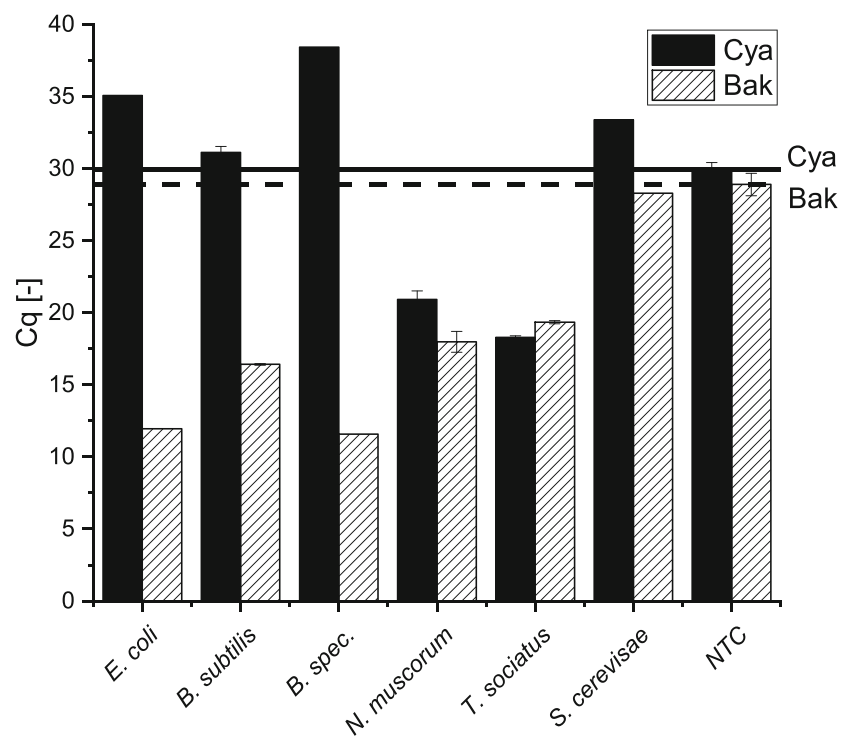

Fig. $1 \mathrm{Cq}$ values of the primers (Cya and Bak) for different microorganisms and a no template control (NTC). The horizontal lines mark the value of the NTC and provide a better overview. N. muscorum and $T$. sociatus as mean and standard deviation of biological quadruplicate in technical triplicate, B. subtilis and NTC as mean of technical triplicate, the others are single measurements specificity of the primers with a larger number of cyanobacteria (23) and bacteria (11). The primer specificity was also successfully tested in silico by Mühling et al. (2008). The Bak primer generated a signal in all bacteria including cyanobacteria below the NTC but not for $S$. cerevisiae. The Bak primer therefore amplifies the DNA of all tested bacteria. This includes the dominant heterotrophic contamination $(B$. sp.) isolated from $T$. sociatus. The melting curves and subsequent gel electrophoresis confirmed the purity of the PCR products. The melting point for the amplicon of primer pair Cya is $86.50{ }^{\circ} \mathrm{C}$, for the amplicon of primer pair Bak $87.50^{\circ} \mathrm{C}$ (see S. 2). The in silico amplicon length for T. sociatus for Cya is $425 \mathrm{bp}$, for Bak $91 \mathrm{bp}$, as was estimated from the gel (see S.1). The efficiency of the primers was determined with a 1:10 dilution series of DNA extracted from $T$. sociatus for Cya with 96\% and for Bak with 107\% (see Fig. 2a). The intra-assay variance between the technical triplicates was $0.28 \%$ for Cya and $0.32 \%$ for Bak. At the lowest still detectable DNA con-

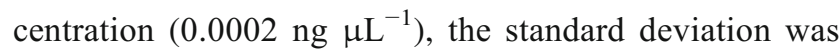
$0.24 \%$ for Cya and $1.21 \%$ for Bak. The presence of a signal at the NTC was caused by primer dimers or similar fragments. The melting curve of the NTC usually showed an undefined peak around $70{ }^{\circ} \mathrm{C}$ (data not shown). To reduce this problem, different primer pairs or an optimized qPCR setup could be tested (Brownie et al. 1997; Elnifro et al. 2000). For the Bak primers, it is also possible that small amounts of DNA from the bacterial production strain of the polymerase are present in the master mix. These would be amplified by the primers (Corless et al. 2000).

To quantify unknown mixtures of bacteria, a standard function of known mixtures was created. Biomass from phototrophic-cultivated cyanobacteria was used, with the assumption that the proportion of heterotrophic bacteria in the biomass was negligible (not the absolute amount of cells). These were mixed with biomass of $B$. subtilis. Bacillus subtilis was chosen because a Bacillus species was identified as the dominant heterotrophic bacterium in the culture of $T$. sociatus (own unpublished results, identified by $16 \mathrm{~S}$ rRNA gene sequencing after cultivation on LB-Agar). The DNA of the samples was extracted and purified and the $\mathrm{Cq}$ values for both primer pairs were determined by qPCR. It was not possible to normalize $\mathrm{Cq}_{\mathrm{Cya}}$ with $\mathrm{Cq}_{\mathrm{Bak}}$, because the latter does not remain constant over the biomass concentration. This was also seen in the measured data (not shown) and can also be explained theoretically. The basic assumption is that the $\mathrm{Cq}_{\mathrm{Bak}}$ depends on the number of 16S rRNA gene sequences (both from cyanobacteria and B. subtilis) in the sample. The same absolute amount of DNA was applied. Thus, $\mathrm{Cq}_{\mathrm{Bak}}$ depends on the amount of 16S rRNA sequences per megabase pair $(\mathrm{Mbp})$. The genome size of cyanobacteria is around $5.66 \pm$ $2.45 \mathrm{Mbp}$ (Louca et al. 2018). The gene copy number of the measured 16S rRNA gene of cyanobacteria is $2.3 \pm 1.2$ (Větrovský and Baldrian 2013). Simplified, this results in 


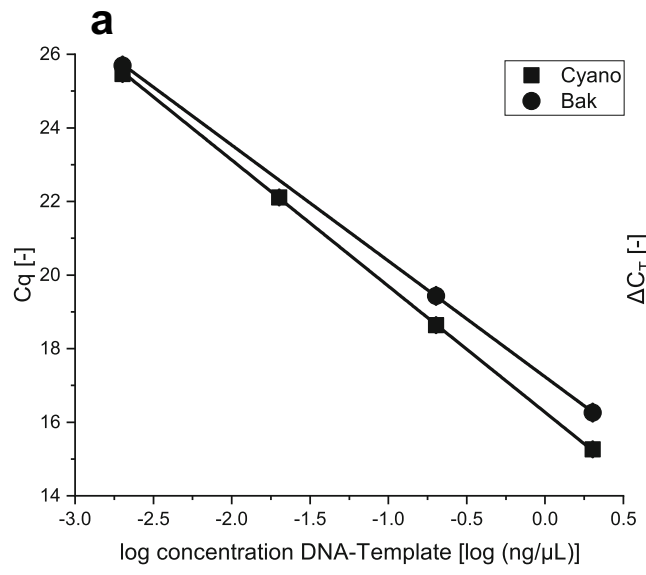

Fig. 2 Left: qPCR threshold $(\mathrm{Cq})$ over the template concentration (gDNA from $T$. sociatus). The efficiency of the primer was calculated from the slopes of the linear fit according to formula 1. Cya primer: offset $16.27 \pm$ 0.04 ; slope $-3.4283 \pm 0.0275$; efficiency $96 \% ; R^{2} 0.999$ ); Bak primer: offset $17.23 \pm 0.01$; slope $-3.1497 \pm 0.0167$; efficiency $108 \%, R^{2} 0.999$ ). Each data point corresponds to the mean and standard deviation of a technical triplicate; right: $\Delta \mathrm{Cq}$ (see Eq. 2) for mixtures of $T$. sociatus

about 0.3 copies per Mbp. The genome of $B$. subtilis is about $4.165 \mathrm{Mbp}$ in size and contains 5 copies, or about 1.2 copies per Mbp (Farrelly et al. 1995). Thus, with an increasing number of $B$. subtilis in the mixture, the amount of gene copies per Mbp in the DNA sample also increases and thus the $\mathrm{Ct}_{\mathrm{Bak}}$ value decreases. The $\mathrm{Ct}_{\mathrm{Cya}}$ value depends only on the cyanobacterial DNA and thus decreases with an increasing amount of cyanobacteria in the mixture (not shown). However, it is not possible to use only the $\mathrm{Ct}_{\text {Bak }}$ or the $\mathrm{Ct}_{\text {Cya }}$ value alone to determine the biomass fraction of the cyanobacteria. The absolute $\mathrm{Ct}$ values of the individual biological samples are subject to certain variability. This is caused by the amount of DNA used, which fluctuates due to possible errors in the DNA measurement as well as pipetting errors. In addition, small amounts of inhibitors or a fluctuating DNA quality/integrity can play a role in the Ct value. Therefore, we use the $\Delta \mathrm{Ct}$ value according to Livak and Schmittgen (2001). The $\Delta \mathrm{Ct}$ varies with the biomass fraction (see Fig. 2b). At a certain biomass fraction, $\Delta \mathrm{Ct}$ should always assume a certain value. We assume that the variation of the samples has an equal influence on the measurements of $\mathrm{Ct}_{\mathrm{Cya}}$ and $\mathrm{Ct}_{\mathrm{Bak}}$. Thus, the difference between the two is therefore always the same. This compensates the variability of the samples. Thus, we can use $\Delta \mathrm{Ct}$ over the biomass fraction to generate a standard function. The data are described using a simple empirical function.

The functions described the data well with a corrected $R$ squared value of 0.98 for $T$. sociatus and 0.99 for N. muscorum. The calibration functions for the two strains under investigation differ. This means that a separate calibration must be created for each additional cyanobacterium strain. For both strains, a biomass fraction of 100-60/

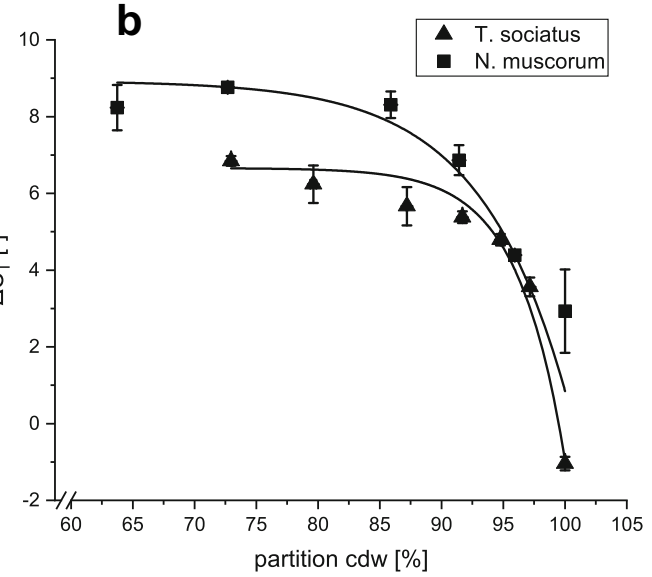

and $N$. muscorum with B. subtilis versus partition of biomass of cyanobacteria of total cdw (see Eq. 4). The measuring points are fitted with Eq. 3. Empirical parameters: T. sociatus: a $-4.12 \times 10^{-11}$, b 3.855 , c $6.658, R^{2} 0.987 ;$. muscorum: $\mathbf{a}-4.12 \times 10^{-11}, \mathbf{b}-7.03$, c $8.93, R^{2} 0.99$. Each data point corresponds to the mean and standard deviation of biological triplicates measured as technical triplicates

$70 \mathrm{wt} \%$ of the respective cyanobacterium was quantified using the functions. The standard series was not tested further than $60 \%$ biomass of the cyanobacterium. This seems acceptable since cultures of less than $60 \%$ are probably not interesting for a bioprocess.

Especially for T. sociatus, it can be seen that even a small proportion of $B$. subtilis biomass has a great influence on the signal. We reason that the cells of $T$. sociatus and $N$. muscorum are relatively large and therefore presumably contain little DNA amounts in relation to their biomass. Both cyanobacteria are coccoidal and have a diameter of 5-6 $\mu \mathrm{m}$, which corresponds to a volume of about $65 \mu \mathrm{m}^{3}$. A rod-shaped bacterium like $B$. subtilis with a length of about $2 \mu \mathrm{m}$ and a diameter of $1.2 \mu \mathrm{m}$ only has a volume of about $2.2 \mu^{3}$. Both cyanobacteria and B. subtilis probably have a similar amount of DNA per cell but different gene copy number of the 16S rRNA gene sequence (see above). A defined amount of biomass of $B$. subtilis thus contains a much higher amount of DNA with a higher concentration of target gene than the same amount of biomass from a cyanobacterium. Small amounts of biomass therefore already have a large impact on the $\Delta \mathrm{Ct}$ value.

\section{Heterotrophic cultivations}

The evolution of biomass composition over time was investigated. For this purpose, T. sociatus was cultivated under heterotrophic conditions with glucose for 14 days. After 2, 5, 7 and 14 days, the biomass composition was determined by qPCR and the cdw was determined (Fig. 3). After 2 days, the proportion of T. sociatus in the biomass is reduced to $90 \%$. The cdw increases from 0.75 to $1.64 \mathrm{~g} \mathrm{~L}^{-1}$ by $0.9 \mathrm{~g} \mathrm{~L}^{-1}$ during the 


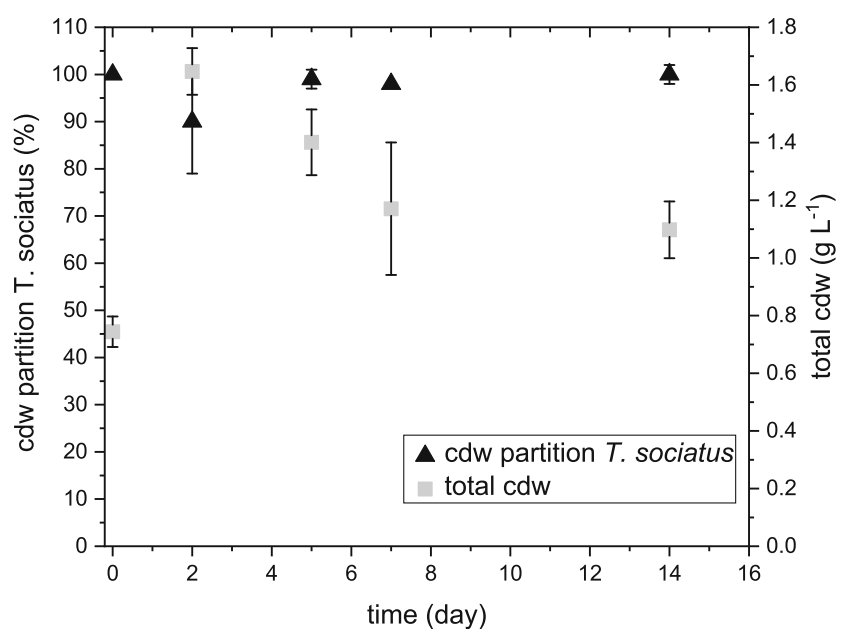

Fig. 3 Time course of the biomass composition and total biomass of a heterotrophic cultivation of $T$. sociatus measured by qPCR. Cultivation over 14 days at $27^{\circ} \mathrm{C}$ with $2.53 \mathrm{~g} \mathrm{~L}^{-1}$ glucose as carbon source. All data points are the mean and standard deviation of biological triplicates

first 2 days of cultivation. Using the qPCR, it can be determined that about $0.73 \mathrm{~g} \mathrm{~L}^{-1}$, or $80 \%$, of the newly produced cdw consists of $T$. sociatus. From this, it can be assumed that about $4 / 5$ of the glucose used is utilized by the cyanobacteria and $1 / 5$ by the heterotrophic bacteria. The results are in good agreement with other studies that show that cyanobacteria grow well on glucose (Markou and Georgakakis 2011; Francisco et al. 2014).

After 2 days, glucose is almost completely consumed in the cultivation media (data not shown). Subsequently, the cyanobacteria displace the heterotrophic bacteria (below $2 \%$ of cdw on day 5). Trichocoleus sociatus has shown antibacterial activity in previous studies (Strieth et al. 2017). With this activity, it seems to be possible to control the growth of the heterotrophic bacteria below the detection limit. It is unclear why the cyanobacterium does not completely eliminate the heterotrophic bacteria. Perhaps this is not its intention at all. Many studies have shown that cyanobacteria live in symbiosis with heterotrophic bacteria. These supply the cyanobacteria with important secondary metabolites and in return receive carbohydrates or nitrogen compounds (Thompson et al. 2012; Kouzuma and Watanabe 2015; Yao et al. 2019).

\section{Conclusion}

For the first time, a qPCR method was presented which is capable of measuring the quantitative composition of cultivations of terrestrial cyanobacteria with a carbohydrate source. By using biomass mixtures as a calibration series, the proportion of cyanobacterial biomass in cultivation can be determined. Due to the universal primers, the method can be easily transferred to new cyanobacterial cultures. However, a new standard curve must be recorded for each strain. This new method is particularly useful in the development of bioprocesses in order to assess the benefits of carbohydrate supplementation. In future cultivations, the development of the biomass composition over the process period can be examined in more detail. In combination with a sugar analysis, it is expected that further knowledge about the consumption of sugar by the different species in cultivation can be gained.

Acknowledgments Open Access funding enabled and organized by Projekt DEAL. Special thanks go to Matthew Aronson for proofreading the manuscript, Michelle Gehringer for providing useful advice on DNA extraction of cyanobacteria and Prof. Dr. Burkhard Büdel for the provided strains.

Funding Funding by the German Research Foundation (DFG: UL 170/ 16-1 and MU 2985/3-1) and the Ministry of Science, Further Education and Culture of Rhineland-Palatinate (mwwk.rlp) (iProcess intelligent process development-from modelling to product) is gratefully acknowledged.

Open Access This article is licensed under a Creative Commons Attribution 4.0 International License, which permits use, sharing, adaptation, distribution and reproduction in any medium or format, as long as you give appropriate credit to the original author(s) and the source, provide a link to the Creative Commons licence, and indicate if changes were made. The images or other third party material in this article are included in the article's Creative Commons licence, unless indicated otherwise in a credit line to the material. If material is not included in the article's Creative Commons licence and your intended use is not permitted by statutory regulation or exceeds the permitted use, you will need to obtain permission directly from the copyright holder. To view a copy of this licence, visit http://creativecommons.org/licenses/by/4.0/.

\section{References}

Allen MM (1968) Simple conditions for growth of unicellular blue-green algae on plates. J Phycol 4:1-4

Arias DM, Rueda E, García-Galán MJ, Uggetti E, García J (2019) Selection of cyanobacteria over green algae in a photo-sequencing batch bioreactor fed with wastewater. Sci Total Environ 653:485495

Brownie J, Shawcross S, Theaker J, Whitcombe D, Ferrie R, Newton C, Little S (1997) The elimination of primer-dimer accumulation in PCR. Nucleic Acids Res 25:3235-3241

Chlipala EG, Mo S, Orjala J (2011) Chemodiversity in freshwater and terrestrial cyanobacteria - a source for drug discovery. CDT 12 : 1654-1673

Chojnacka K, Noworyta A (2004) Evaluation of Spirulina sp. growth in photoautotrophic, heterotrophic and mixotrophic cultures. Enz Microb Technol 34:461-465

Corless CE, Guiver M, Borrow R, Edwards-Jones V, Kaczmarski EB, Fox AJ (2000) Contamination and sensitivity issues with a real-time universal 16S rRNA PCR. J Clin Microbiol 38:1747-1752

Elnifro EM, Ashshi AM, Cooper RJ, Klapper PE (2000) Multiplex PCR: optimization and application in diagnostic virology. Clin Microbiol Rev 13:559-570

Farrelly V, Rainey FA, Stackebrandt E (1995) Effect of genome size and rrn gene copy number on PCR amplification of 16S rRNA genes 
from a mixture of bacterial species. Appl Environ Microbiol 61: 2798-2801

Ferris MJ, Hirsch CF (1991) Method for isolation and purification of cyanobacteria. Appl Environ Microbiol 57:1448-1452

Francisco ÉC, Franco TT, Wagner R, Jacob-Lopes E (2014) Assessment of different carbohydrates as exogenous carbon source in cultivation of cyanobacteria. Bioprocess Biosyst Eng 37:1497-1505

Gantar M, Kaczmarsky LT, Stanić D, Miller AW, Richardson LL (2011) Antibacterial activity of marine and black band disease cyanobacteria against coral-associated bacteria. Mar Drugs 9: 2089-2105

Garcia-Pichel F, López-Cortés A, Nübel U (2001) Phylogenetic and morphological diversity of cyanobacteria in soil desert crusts from the Colorado plateau. Appl Environ Microbiol 67:1902-1910

Heck K, Machineski GS, Alvarenga DO, Vaz MGMV, Varani AM, Fiore MF (2016) Evaluating methods for purifying cyanobacterial cultures by $\mathrm{qPCR}$ and high-throughput Illumina sequencing. J Microbiol Meth 129:55-60

Keith JM (ed) (2008) Bioinformatics. Methods in molecular biology, Vol 453. Humana Press, Totowa, NJ

Kinghorn AD, Blanco EJC, de Lucas DM, Rakotondraibe HL, Orjala J, Soejarto DD, Oberlies NH, Pearce CJ, Wani MC, Stockwell BR, Burdette JE, Swanson SM, Fuchs JR, Phelps MA, Xu L, Zhang X, Shen YY (2016) Discovery of anticancer agents of diverse natural origin. Anticancer Res 36:5623-5637

Kouzuma A, Watanabe K (2015) Exploring the potential of algae/bacteria interactions. Curr Opin Biotechnol 33:125-129

Kuhne S, Strieth D, Weber A, Muffler K, Lakatos M, Ulber R (2014) Screening of two terrestrial cyanobacteria for biotechnological production processes in shaking flasks, bubble columns, and stirred tank reactors. J Appl Phycol 26:1639-1648

Lamprinou V, Tryfinopoulou K, Velonakis E, Vatopoulos A, Antonopoulou S, Fragopoulou E, Pantazidou A, Economou-Amilli A (2015) Cave cyanobacteria showing antibacterial activity. Int J Speleol 44:231-238

Livak KJ, Schmittgen TD (2001) Analysis of relative gene expression data using real-time quantitative PCR and the 2- $\Delta \Delta \mathrm{CT}$ method. Methods 25:402-408

Louca S, Doebeli M, Parfrey LW (2018) Correcting for 16S rRNA gene copy numbers in microbiome surveys remains an unsolved problem. Microbiome 6:41

Markham NR, Zuker M (2005) DINAMelt web server for nucleic acid melting prediction. Nucleic Acids Res 33:W577-W581

Markou G, Georgakakis D (2011) Cultivation of filamentous cyanobacteria (blue-green algae) in agro-industrial wastes and wastewaters: a review. Appl Energy 88:3389-3401

Mühling M, Woolven-Allen J, Murrell JC, Joint I (2008) Improved group-specific PCR primers for denaturing gradient gel electrophoresis analysis of the genetic diversity of complex microbial communities. ISME J 2:379-392

Nübel U, Garcia-Pichel F, Muyzer G (1997) PCR primers to amplify 16 S rRNA genes from cyanobacteria. Appl Environ Microbiol 63:33273332
Pacheco ABF, Guedes IA, Azevedo SMFO (2016) Is qPCR a reliable indicator of cyanotoxin risk in freshwater? Toxins (Basel) 8. https:// doi.org/10.3390/toxins 8060172

Palinska KA, Krumbein WE (1995) Electrophoretic separation of two unicyanobacterial strains leading to purification. J Microbiol Meth 24:41-48

Porter RD (1988) [78] DNA transformation. Meth Enzymol 167:703-712

Strieth D, Schwing J, Kuhne S, Lakatos M, Muffler K, Ulber R (2017) A semi-continuous process based on an ePBR for the production of EPS using Trichocoleus sociatus. J Biotechnol 256:6-12

Strieth D, Ulber R, Muffler K (2018) Application of phototrophic biofilms: from fundamentals to processes. Bioproc Biosyst Eng 41:295-312

Svec D, Tichopad A, Novosadova V, Pfaffl MW, Kubista M (2015) How good is a PCR efficiency estimate: recommendations for precise and robust qPCR efficiency assessments. Biomol Detect Quantif 3:9-16

Swain SS, Paidesetty SK, Padhy RN (2017) Antibacterial, antifungal and antimycobacterial compounds from cyanobacteria. Biomed Pharmacother 90:760-776

Temraleeva AD, Dronova SA, Moskalenko SV, Didovich SV (2016) Modern methods for isolation, purification, and cultivation of soil cyanobacteria. Microbiology 85:389-399

Thompson AW, Foster RA, Krupke A, Carter BJ, Musat N, Vaulot D, Kuypers MMM, Zehr JP (2012) Unicellular cyanobacterium symbiotic with a single-celled eukaryotic alga. Science 337:1546-1550

Tillett D, Neilan BA (2000) Xanthogenate nucleic acid isolation from cultured and environmental cyanobacteria. J Phycol 36:251-258

Trabelsi L, Ben Ouada H, Zili F, Mazhoud N, Ammar J (2013) Evaluation of Arthrospira platensis extracellular polymeric substances production in photoautotrophic, heterotrophic and mixotrophic conditions. Folia Microbiol 58:39-45

Vasquez-Martinez G, Rodriguez MH, Hernandez-Hernandez F, Ibarra JE (2004) Strategy to obtain axenic cultures from field-collected samples of the cyanobacterium Phormidium animalis. J Microbiol Meth $57: 115-121$

Větrovský T, Baldrian P (2013) The variability of the 16S rRNA gene in bacterial genomes and its consequences for bacterial community analyses. PLoS One 8:e57923

Yao S, Lyu S, An Y, Lu J, Gjermansen C, Schramm A (2019) Microalgae-bacteria symbiosis in microalgal growth and biofuel production: a review. J Appl Microbiol 126:359-368

Yu H, Jia S, Dai Y (2009) Growth characteristics of the cyanobacterium Nostoc flagelliforme in photoautotrophic, mixotrophic and heterotrophic cultivation. J Appl Phycol 21:127-133

Zhang W, Lou I, Ung WK, Kong Y, Mok KM (2014) Application of PCR and real-time PCR for monitoring cyanobacteria, Microcystis spp. and Cylindrospermopsis raciborskii in Macau freshwater reservoir. Front Earth Sci 8:291-301

Zhou Y, Eustance E, Straka L, Lai YS, Xia S, Rittmann BE (2018) Quantification of heterotrophic bacteria during the growth of Synechocystis sp. PCC 6803 using fluorescence activated cell sorting and microscopy. Algal Res 30:94-100

Publisher's note Springer Nature remains neutral with regard to jurisdictional claims in published maps and institutional affiliations. 